\title{
Decision support system design based building roof and structure selection for building contractors
}

\author{
Mahziyar Ghazizahedi' \\ Mohmmad Khalily Dermany"
}

\begin{abstract}
The contractors must consider the structure ability to cope and resist against accidental phenomena such as earthquake, flood, storm or fire, during the structure service life. In this way, the major losses of life and property are prevented as far as possible. In this regard, the building roof and structure selection is of great importance among contractors.

The main objective of this research is to provide a model for building contractors for building roof and structure selection using the decision support system. Accordingly, a decision support system is designed for building contractors to select the building roof and structure using analytical Hierarchy process (AHP) and VIKOR techniques. The data were collected using a questionnaire.
\end{abstract}

Keywords: Contractors; Building roof and structure; Decision support system; Analytical hierarchy process (AHP) method; VIKOR; Fuzzy theory

I Departmant of Electronic commerce, Khomein Branch, Islamic Azad University, Khomein, Iran m.ghazizahedi@yahoo.com

"Assistant Professor, Young Researchers and Elite Club, Khomein Branch, Islamic Azad University, Khomein, Iran Corresponding author - md.khalili@gmail.com 


\section{Introduction}

The force entered to a building in an earthquake takes effect from its mass or weight. Hence, the more weight the building is and the heavier materials are used, the more forces will enter to the building. (1). One factor that could contribute to lighten the weight of the building, is the weight of structure. Therefore, the selection of the type of roof and structure depends on factors such as the employer's financial capability, structural sensitivity, the distance between the columns openings, time, structural strength, structural use, structural position, and so on. On the other hand, bearing systems of the building are also of great importance and the roof cannot be selected for each structure optionally. IT requires the calculation of the lateral load weight and stresses on the columns, etc. The building system selection is characterized by a variety of characteristics that make its selection appropriate using multi-criteria decision-making methods (2). Because of this, the building roof and structure selection, either in terms of design and computing, or in terms of quality and construction time is complex. Using a decision support system can help reduce costs and increase productivity significantly. Smartly selection of optimal decision in tasks is very important to projects in terms of time and economics (3).

Today, with the introduction of new structural systems to the construction industry and the competition of these systems, it is not too easy to decide on the most suitable building system in a project, despite the traditional and common structural systems. This is one of the major challenges and issues in construction engineering and management of these kinds of projects, especially in Iran, (4). Most of multi-criteria decision-making techniques are not sufficiently complete. This reduces the incremental trend of use of combined methods in which two or more separate methods are implemented together (5). The main objective of this research is to design a decision support system for building contractors to select the building roof and structure. In this system, alternatives (building roof and structure) are ranked, taking into account the conditions of uncertainty, with the help of Fuzzy Theory and using Fuzzy VIKOR. For this purpose, the weight and rank of the factors influencing these alternatives are ranked by using the Fuzzy AHP method. Since each of these factors does not have the same importance and relationship, the relationship and 
dependence between the factors affecting the building roof and structure selection are determined using Fuzzy AHP method.

Therefore, in this study, a decision support system is designed for building contractors to select the building roof and structure. We will also study the research conducted on this subject. In addition, the factors affecting the building roof and structure selection will be ranked using Fuzzy AHP and VIKOR techniques.

\section{Literature review}

In his study (4), the author has used the multi-criteria decision-making method to select the appropriate building system. In this research, a combination of ELECTRE III and PROMETHEE multi-criteria decision-making methods with an interval approach for the selection of suitable building system has been introduced. In the proposed method, weights of criteria, thresholds of excellence, and indifference and rejection were obtained by the decision makers and using some questionnaires. All three groups of decision makers including employer, consultant and contractor, considered the lightweight steel structure (LSF) building system as the selected building system. The results of this study indicate that the proposed method can be very effective to select the appropriate building system. This method can be used in other fields of construction engineering and management by observing the required parameters.

In (6), the authors have used the group multi-criteria decision-making method to select the appropriate building system. They have introduced a number of new building systems and expressed their various evaluation indicators, such as indicators of structural and seismic evaluation, energy, service life and strength, architecture, safety, industrial and economic production, and environment. Also, they have investigated how to select the best system among them using the group AHP multi-criteria decision-making approach, considering the opinions of experts and decision makers, including advisors and contractors, in the decision-making process.

In (7), the authors have identified the factors affecting the competitive advantage of companies active in the construction industry. They have surveyed the factors affecting 
competitive advantage in five areas of infrastructure, technology, human resources, procurement, and, finally, the main activities of design and implementation that have been derived from Porter's Value Chain Theory. Based on their results, new methods of design and construction, as well as taking advantage of new methods and technologies in building construction have created the attractiveness for building and increased the customer satisfaction. This provides constructors with a positive opportunity to gain competitive advantage.

In (8), the authors have used multi-criteria decision-making methods including AHP, Simple additive weighting (SAW) and TOPSIS to solve the problem of optimal building system selection. Based on the results, the use of different decision-making techniques will bear relatively similar results. So that using all three methods of multi-criteria decisionmaking, the concrete precast system was ranked first and the cold-formed lightweight steel frame system was ranked second. Also, the concrete precast system was ranked first in terms of performance and economic criteria, and the cold-formed lightweight steel frame system was ranked first in terms of environmental criteria.

In (5), the authors have examined the use of multi-criteria decision-making methods in construction management. In their belief, the construction is a research case in which decision-making is the difference between success and failure. In their research, they investigate implementation cases statistically and using multi-criteria decision-making techniques. This study proves the usefulness of these techniques in categorizing different decision-making environments.

The authors in (9) have provided a multi-criteria decision-making system for evaluating sustainable buildings. They have proposed a multi-criteria evaluation (MCE) system to assess sustainable buildings using these methods. According to the results obtained by the exploration of the literature, the criteria for sustainability in architecture are divided into three general categories: environmental, economic and social. The pair-wise comparisons of AHP in this study showed that the most important criteria are environmental ones. Environmental sub-criteria are: energy consumption, proportionality, waste, recycling criteria, pollution and resource consumption. 
The authors in (10) introduced an AHP model to evaluate the resistance and stability of bridge construction different methods. They believe that one of the major challenges in architecture is environmentally friendliness, so that this precious heritage is least damaged, since the human health and survival depends on its health. To protect this precious heritage, appropriate strategies for architectural design and adopting rational approaches to decision-making can be used.

The authors in (11) concluded that lightweight and folding structures have a very high load capacity. These structures, the least amount of material is used. Also, the idea of compatible structures can be of the most important ways of achieving sustainability. Such structures adapt to changing needs such as technological advances.

The authors in (12) argue that today, with the introduction of modern building systems to the construction industry and competition of these systems, it is not too easy to decide on applying the most appropriate building system in a project, despite the traditional and common building systems. This is one of the major challenges and issues in construction engineering and management of these types of projects. In their research, they have examined the impact of sustainable construction materials on the construction industry. In this study, the main objective is to present a model for optimal selection of sustainable raw and construction materials in order to achieve optimal cost and design. Their research results indicate that the selection of raw materials has a significant effect on the sustainability of the green building industry.

In (13), the authors have developed an AHP technique to strengthen the process of selecting sustainable materials for construction projects. In this study, triangular fuzzy numbers-based AHP method was used to consider three strength columns, so that the priorities among the criteria are determined. Then, these criteria were combined through extensive material analysis.

In (14), the authors have investigated the selection criteria for construction equipment and machinery. In their paper, they have studied the impact of equipment and machinery selection on this industry performance and effectiveness. Based on their research, the equipment and machinery selection has a significant effect on performance and 
effectiveness, and it must conform to the principles of sustainable architecture, to be effective and optimize performance.

\subsection{Fuzzy Logic}

The Fuzzy Sets Theory can express many of the imprecise concepts and phrases in mathematical language. It provides a ground for reasoning, inference, control, and decision making in conditions of uncertainty (15).

According to this theory, a fuzzy number is a specific fuzzy set $\tilde{A}=\frac{x \in R}{\mu_{\widetilde{A}}(x)}$ in which $\mathrm{x}$ accepts the real member values of set $\mathrm{R}$ and its membership function (MF) is $\mu_{\tilde{A}}(x)$. The most commonly used fuzzy numbers are triangular and trapezoidal fuzzy ones. Triangular fuzzy numbers are used more for simpler calculations. A triangular fuzzy number $\tilde{A}=\left(a^{i} ; a^{m} ; a^{u}\right)$ is a piecewise linear numerical membership function, defined by Equation 1:

$\mu_{x}(x)=\left\{\begin{array}{cc}\left(x-a^{l}\right) /\left(a^{m}-a^{l}\right), & a^{l} \leq x<a^{m} \\ 1, & x=a^{m} \\ \left(a^{r}-x\right) /\left(a^{r}-a^{m}\right), & a^{m}<x \leq a^{r} \\ 0, & \text { otherwise }\end{array}\right.$

If $\tilde{A}=\left(a^{i} ; a^{m} ; a^{u}\right)$ and $\tilde{B}=\left(b^{i} ; b^{m} ; b^{u}\right)$ are two triangular fuzzy numbers, then the distance function $d(\tilde{A} ; \tilde{B})$ is defined by Equation 2:

$d(\tilde{A} ; \tilde{B})=\sqrt{\frac{1}{3}\left(\left(a^{i}-b^{i}\right)^{2}+\left(a^{m}-b^{m}\right)^{2}+\left(a^{u}-b^{u}\right)^{2}\right)}$

Fuzzy logic makes possible the conventional ways of designing and modeling a network that requires advanced and relatively complex mathematics, using linguistic values and variables. For this reason, it has a special place in quantitative risk analysis methods.

\subsection{Decision support system}


Decision-making is one of the most important tasks for experts and managers. Their ability to analyze data in order to make optimal decisions plays an important role in management and organization success and effectiveness (16). In the general and summary definition by Liang (2007), these systems are defined as a subset of information systems that can analyze past behaviors and make recommendations for current issues.

With the decision support system, the lack of information can be compensated, so that managers can improve the quality of their decisions. For this, the latest innovations in technology (hardware and software) should be used (16).

\subsection{Analytical Hierarchy Process (AHP)}

For years, Multi-criteria decision-making methods play a major role in decision science, in which selecting a solution among existing solutions and prioritizing them are desired. Of these, AHP method is used more than others in management science. It is argued by systems theorists that complex relationships in AHP can be analyzed by pair-wise comparisons of components and establishing relationships between them based on their characteristics. Comparison tables are made from the bottom to the top based on the hierarchy tree, and a pair-wise comparison is performed using a scale designed from the same preferred (numerical value 1) to extremely preferred (numerical value 9). One method for combining comparison tables is the use of geometric average. In this case, we assume that $a_{i j}^{k}$ is the component of the k-th person for comparison of $\mathrm{i}$ with $\mathrm{j}$. Therefore, the geometric average is calculated for all the corresponding components according to Equation 3:

$\bar{a}_{i j}=\left(\prod_{k=1}^{N} a_{i j}^{k}\right)^{N}$

The above equation is used when the comments of the members are of equal importance. But if we do not accept this assumption and give each person a special importance coefficient, then the components of the group matrix will be calculated by the following equation: 


$$
\bar{a}_{i j}=\left(\prod_{k=1}^{N} a_{i j}^{W_{k}}\right)^{\frac{1}{N}}
$$

So that $\sum_{k=1}^{L} W_{k}=N$

For the extraction of priorities, just group comparison matrices are considered. In a hierarchical analysis method, the following equation is used to normalize the numbers of the comparison matrices, in which ${ }^{r_{i j}}$ is the normalized component, which is obtained on the basis of an hourly norm.

$$
r_{i j}=\frac{\bar{a}_{i j}}{\sum_{i=1}^{m} \bar{a}_{i j}}
$$

Following the normalizing, weighted average of the values of each row is taken. The values of the weighted average indicate the priority (degree of importance) of each general indicator to the other (17).

\subsection{VIKOR method}

In this method, the compromise solution is the closest solution to the ideal alternative. The VIKOR method has been developed for multi-criteria optimization of complex systems. This approach is based on the compromise programming of multi-criteria decision-making problems and evaluates issues with disproportionate and incompatible criteria. In this method, a ranking list is provided based on the distance between the criteria and the ideal point. The decision matrix is formed as follows, regarding the number of criteria, the number of alternatives, and the evaluation of all alternatives for different criteria:

$X=\left[\begin{array}{ccc}x_{11} & \cdots & x_{1 n} \\ \vdots & \ddots & \vdots \\ x_{m 1} & \cdots & x_{m n}\end{array}\right]$

In this matrix, $x_{i j}$ is the function of alternative i versus the criterion $\mathrm{j}$. At this stage, we try to transform the criteria with different dimensions into unscaled ones, and the matrix $\mathrm{F}$ is defined as: 
$F=\left[\begin{array}{ccc}f_{11} & \cdots & f_{1 n} \\ \vdots & \ddots & \vdots \\ f_{1 m} & \cdots & f_{m n}\end{array}\right]$

In this matrix

$f_{i j}=\frac{x_{i j}}{\sqrt{\sum_{i=1}^{m} x_{i j}^{2}}}$

Then, considering the importance coefficient of the various criteria in decisionmaking, a vector is defined as:

$w=\left(w_{1}, w_{2}, \ldots w_{n}\right)$

In the next step, the best and worst values are determined, and $f_{j}^{*}$ and $f_{j}^{-}$are determined for all criteria. For example, if $i$-th criterion is indicative of a positive criterion, we will have:

$f_{j}^{*}=\max _{i j} ; f_{j}^{-}=\operatorname{minf}_{i j}$

In the case of negative criteria, the best and worst values are determined as follows:

$f_{j}^{*}=\operatorname{minf}_{i j} ; f_{j}^{-}=\max _{i j}$

Therefore, the distances $S_{i}$ and $R_{i}$ are calculated using the following equations:

$\sum_{i=1}^{n} w_{j} \frac{f_{j}^{*}-f_{i j}}{f_{j}^{*}-f_{j}^{-}}=S_{i}$

$R_{i}=\max \left[w_{j} \frac{f_{j}^{*}-f_{i j}}{f_{j}^{*}-f_{j}^{-}}\right]$

In the above equations, $w_{j}$ is the weights of the criteria and donates their relative importance. $S_{i}$ and $R_{i}$ are in the interval $(0,1), 0$ is the indicator of the best mode, and 1 is 
that of the worst mode. $S_{i}$ is interpreted as concordance or utility measure. It can provide information about the maximum group utility or majority. $R_{i}$ is also defined as discordance or regret measure and provides information about the minimum regret to the decision makers. The distance $Q_{i}$ will be calculated to calculate the VIKOR index ( $Q$ value), in order to rank the alternatives considered. $Q_{i}$ is obtained by the following equation:

$Q_{i}=v \frac{S_{i}-S^{*}}{S^{-}-S^{*}}+(1-v) \frac{R_{i}-R^{*}}{R^{-}-R^{*}}$

In this case, $v$ belongs to the interval $(0,1)$, which is called the strategy weight of the of the majority of the criteria (or maximum group utility) and is usually 0.5 . Also, in the above equation, $S^{*}=\min _{i}, S=\max S_{i}, R^{*}=\min R_{i}$ and $R=\max R_{i}$. In the above equation, $\frac{S^{*}-S^{-}}{S_{i}-S^{-}}$ donates the distance from the ideal solution and $\frac{R^{*}-R^{-}}{R_{i}-R^{-}}$indicates the distance from the antiideal solution. The parameter $v$ is also selected according to the compromise of the decision maker group. In the case of a high compromise, it is more than 0.5 , in the case of a compromise by the majority, it is equal to 0.5 , and if the compromise is low, it is less than 0.5 .

The best alternative with the lowest $Q_{i}$ is achieved under the conditions in which the following two conditions are met:

The first condition - Acceptance Feature: The following equation must be true about the selected alternative.

$$
\begin{aligned}
& Q\left(A^{2}\right)-Q\left(A^{1}\right) \geq D Q \\
& D Q=\frac{1}{n-1}
\end{aligned}
$$

Here, $A^{2}$ is an alternative that is ranked second based on the $\mathrm{Q}$ criterion. $A^{1}$ is also the best alternative with the lowest $\mathrm{Q}$ value, and $\mathrm{n}$ is the number of alternatives.

The second condition - acceptable consistency in decision-making

The alternative $A^{1}$ should also have the best rank in $S$ or $R$ indicator ranking.

If one of the above conditions is not met, then a compromise solution set is presented:

If only the second condition is not met, the alternatives $A^{1}$ and $A^{2}$

If the first condition is not met, the alternatives $A^{1}, A^{2}$ and $A^{m}$ 
Here $A^{m}$ is an alternative in the $\mathrm{m}$-th position, in which the following equation is true (Saleh, 2016):

$$
Q\left(A^{m}\right)-Q\left(A^{1}\right)<D Q
$$

\section{Research methodology}

The present study aims to rank the types of building roof and structure. To this end, a number of alternatives and factors affecting their selection are introduced. Data are collected using a questionnaire, after verifying its validity and reliability. The theoretical foundations of the research are obtained from the library method. Factors affecting the building roof and structure selection are weighted and ranked using the Fuzzy AHP method. The types of building roof and structure are ranked taking into account the weights of the previous order and using the Fuzzy VIKOR method. With regard to the results of Fuzzy AHP and Fuzzy VIKOR methods, appropriate solutions to promote the level of contractors are presented. The first questionnaire is related to Fuzzy AHP method and consists of two main parts. The first part consists of demographic questions, and the second part includes 15 questions on the factors affecting the building roof and structure selection, which is designed based on pair-wise comparisons and linguistic variables. In this questionnaire, respondents are asked to compare the importance of each factor in comparison to other factors in a pair-wise way. The method of scoring is presented in Table 1.

The second questionnaire is related to Fuzzy VIKOR method, in which respondents are asked to determine the importance of each of the 15 factors in building roof and structure selection using linguistic variables provided in Table 1.

Table 1 - Introduction of linguistic variables

\begin{tabular}{c|c|c}
\hline Fuzzy number & Abbreviation & Linguistic variables \\
\hline$) 3 \cdot 1 \cdot 1($ & $\mathrm{VL}$ & Very low importance \\
\hline
\end{tabular}




\begin{tabular}{c|c|c}
\hline$) 5 \cdot 3 \cdot 1($ & $\mathrm{L}$ & Low importance \\
\hline$) 7 \cdot 5 \cdot 3($ & $\mathrm{M}$ & Medium importance \\
\hline $5 \cdot 7 \cdot 5($ & $\mathrm{G}$ & Great Importance \\
\hline $969 \cdot 7($ & $\mathrm{VG}$ & $\begin{array}{l}\text { Very great } \\
\text { importance }\end{array}$ \\
\hline
\end{tabular}

Table 2 - Alternatives for building roof and structure selection

\begin{tabular}{|c|c|c|}
\hline Structure & Roof & Row \\
\hline Steel & Barrel vault & 1 \\
\hline Brick & Barrel vault & 2 \\
\hline Concrete & $\begin{array}{c}\text { Concrete slab (one way } \\
\text { and two way) }\end{array}$ & 3 \\
\hline Brick & Block and joist & 4 \\
\hline Steel & Block and joist & 5 \\
\hline Concrete & Block and joist & 6 \\
\hline Nut and bolt & Block and joist & 7 \\
\hline Nut and bolt & Composite & 8 \\
\hline Steel & Composite & 9 \\
\hline Concrete & Prestressed joist & 10 \\
\hline Concrete & Chromite & 11 \\
\hline Steel & Chromite & 12 \\
\hline Brick & Chromite & 13 \\
\hline Nut and bolt & Chromite & 14 \\
\hline Nut and bolt & Steel deck & 15 \\
\hline Steel & Steel deck & 16 \\
\hline Concrete & $\begin{array}{c}\text { Voided biaxial slab } \\
\text { (Cobiax) }\end{array}$ & 17 \\
\hline Concrete & Roofix & 18 \\
\hline Steel & Roofix & 19 \\
\hline Nut and bolt & Roofix & 20 \\
\hline
\end{tabular}


The AHP method is used to rank the criteria affecting the building roof and structure selection. This method is based on the pair-wise comparisons, in which an $11 \times 11$ matrix is formed due to the existence of 11 factors $(n=11)$.

It should also be mentioned that all the factors affecting the building roof and structure selection are of a positive type. The Fuzzy VIKOR method is used to rank the building roof and structure alternatives. The weights obtained in the AHP method should be used to implement these methods. Accordingly, a $20 \times 11$ matrix is formed due to the existence of 11 factors and 20 alternatives $(n=11, m=20)$.

\section{Results}

\subsection{Coding the research variables}

In this study, the factors affecting the building roof and structure selection and the building roof and structure alternatives were extracted from reliable sources and papers and confirmed by specialists and experts. Each of these indicators was coded for to conduct research steps. How to code is given In Tables 3 and 4.

Table 3 - Coding factors affecting the building roof and structure selection

\begin{tabular}{c|c}
\hline Code & Factor \\
\hline F1 & Acoustic and thermal insulation \\
\hline F2 & Strength against fire \\
\hline F3 & Lightweightness \\
\hline F4 & Smoothness \\
\hline F5 & Reduced additional costs and equipment required \\
\hline F6 & Fast and easy construction \\
\hline F7 & The possibility of concurrent construction \\
\hline F8 & The integrity of the roof and structure \\
\hline F9 & Reduced material consumption \\
\hline
\end{tabular}




\begin{tabular}{c|c}
\hline F10 & Reduced time required for construction \\
\hline F11 & Expert required \\
\hline
\end{tabular}

Table 4 - Coding the building roof and structure criteria

\begin{tabular}{l|c}
\hline Code & Alternative \\
\hline A1 & The barrel vault roof with steel structure \\
\hline A2 & The barrel vault roof with brick structure \\
\hline A3 & Concrete slab roof (one way and two way) with concrete structure \\
\hline A4 & Block and joist roof with brick structure \\
\hline A5 & Block and joist roof with steel structure \\
\hline A6 & Block and joist roof with concrete structure \\
\hline A7 & Block and joist roof with bolted structure \\
\hline A8 & Composite roof with bolted structure \\
\hline A9 & Composite roof with steel structure \\
\hline A10 & Prestressed block and joist roof with concrete structure \\
\hline A11 & Chromite roof with concrete structure \\
\hline
\end{tabular}

\subsection{Ranking the factors affecting the building roof and structure selection}

In the Fuzzy AHP method, after generating hierarchical diagram, the decision maker (or decision makers) is asked to compare the elements of each level with each other and to express the relative importance of the elements using fuzzy numbers (18). This diagram can be seen in Figure 1.

Figure 1 - Hierarchical diagram of indicators ranking

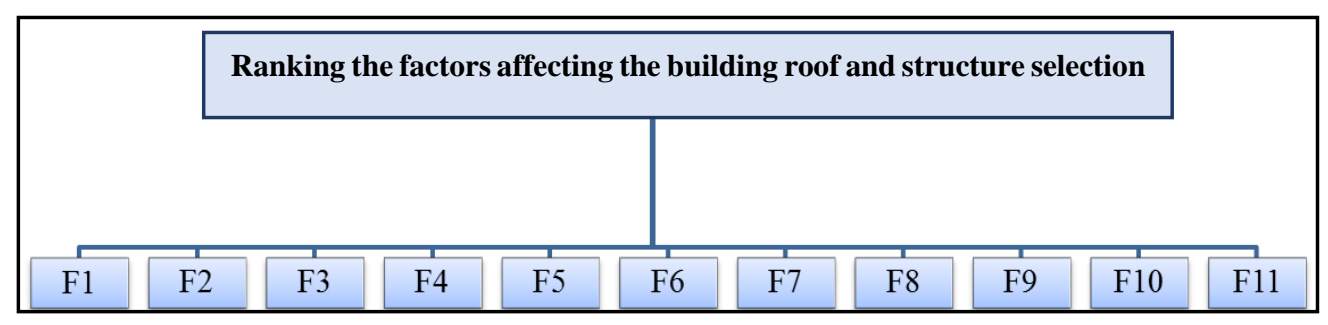


In Fuzzy AHP method, linguistic words are defined for comparison of criteria. In this research, the words are defined as triangular fuzzy numbers. In the mentioned table, the decision maker declares its opinion on each of the criteria using linguistic variables in a 6point spectrum as the set $S=\{V L, L, M, G, V G\}$. In this set, $V L$ is equivalent to "very low importance" with triangular fuzzy numbers $(1,1,3), L$ is equivalent to "low importance" with triangular fuzzy numbers $(1,3,5), M$ is equivalent to "medium importance" with triangular fuzzy numbers $(3,5,7), G$ is "great importance" with triangular fuzzy numbers $(5,7,9)$, and VG is "very great importance" with triangular fuzzy numbers $(7,9,9)$. The summary of the importance and fuzzy numbers associated with each one is given in Table 1.

The rows of the normal matrix must be averaged to calculate the final weight vector. The average of two fuzzy numbers is defined as:

$\frac{M_{1} \oplus M_{2}}{2}=\left(\frac{l_{1}+l_{2}}{2}, \frac{m_{1}+m_{2}}{2}, \frac{u_{1}+u_{2}}{2}\right)$

The values of this step are given in Table 5 and indicate the priority and importance of these indicators.

Table 5 - Fuzzy importance of indicators by Fuzzy AHP method

\begin{tabular}{c|c}
\hline Row average & Factors \\
\hline$(0.068,0.144,0.320)$ & $F 1$ \\
\hline$(0.055,0.117,0.260)$ & $F 2$ \\
\hline$(0.047,0.102,0.244)$ & $F 3$ \\
\hline$(0.053,0.102,0.219)$ & $F 4$ \\
\hline$(0.030,0.071,0.183)$ & $F 5$ \\
\hline$(0.032,0.068,0.147)$ & $F 6$ \\
\hline$(0.078,0.156,0.357)$ & $F 7$ \\
\hline$(0.018,0.053,0.122)$ & $F 8$ \\
\hline$(0.044,0.095,0.185)$ & $F 9$ \\
\hline$(0.024,0.049,0.096)$ & $F 10$ \\
\hline$(0.018,0.043,0.084)$ & $F 11$ \\
\hline
\end{tabular}


Fuzzy numbers are then covert to definite numbers. To this end, the following equation is used.

$\frac{l_{1}+4 m_{1}+u_{1}}{6}$

The results of this step are shown in Table 6.

Table 6 - Ranking of indicators by Fuzzy AHP method

\begin{tabular}{l|c|c}
\hline Ranking & Row average & Factors \\
\hline 2 & 0.160415 & $\mathrm{~F} 1$ \\
\hline 3 & 0.130506 & $\mathrm{~F} 2$ \\
\hline 4 & 0.116487 & $\mathrm{~F} 3$ \\
\hline 5 & 0.113401 & $\mathrm{~F} 4$ \\
\hline 7 & 0.082956 & $\mathrm{~F} 5$ \\
\hline 8 & 0.075091 & $\mathrm{~F} 6$ \\
\hline 1 & 0.176656 & $\mathrm{~F} 7$ \\
\hline 9 & 0.058737 & $\mathrm{~F} 8$ \\
\hline 6 & 0.101343 & $\mathrm{~F} 9$ \\
\hline 10 & 0.052516 & $\mathrm{~F} 10$ \\
\hline 11 & 0.045858 & $\mathrm{~F} 11$ \\
\hline
\end{tabular}

The ranking and priority of the factors affecting the building roof and structure using the Fuzzy AHP method are as follows:

The possibility of concurrent construction

Acoustic and thermal insulation

Strength against fire

Lightweightness

Smoothness

Reduced material consumption 
Reduced additional costs and equipment required

Fast and easy construction

The integrity of the roof and structure

Reduced time required for construction

Expert required

Ranking alternatives for the building roof and structure selection using Fuzzy VIKOR method

In this method, first, the collected comments, which are linguistic variables, are converted to fuzzy numbers according to Table 1, and then the calculations are performed on fuzzy numbers. The decision matrix is an $11 \times 20$ one, with 11 factors and 20 alternatives. According to the number of criteria, the number of alternatives, and the evaluation of all alternatives for different criteria, the decision matrix is formed as follows:

$X=\left[\begin{array}{ccc}x_{11} & \cdots & x_{111} \\ \vdots & \ddots & \vdots \\ x_{201} & \cdots & x_{2011}\end{array}\right]$

In this matrix, $x_{i j}$ is the impact level of the criterion $\mathrm{j}$ on the performance of the alternative i.

The best and worst values are determined, and $f_{j}^{*}$ and $f_{j}^{-}$are determined for all criteria. Given that all criteria are positive, we have:

$f_{j}^{*}=\max _{i j} ; f_{j}^{-}=\operatorname{minf}_{i j}$

These values are given in Table 7.

Table 7 - The best and worst values in Fuzzy VIKOR method

\begin{tabular}{c|c|c}
\hline $\begin{array}{c}\text { The worst } \\
\text { value }\end{array}$ & The best value & Factor \\
\hline$(0.31,1,3.27)$ & $(1.5,12.3,31.5)$ & $\mathrm{F} 1$ \\
\hline$(0.54,1,1.87)$ & $(30,53.1,72.5)$ & $\mathrm{F} 2$ \\
\hline$(0.22,1,4.64)$ & $(1.43,3,8.53)$ & $\mathrm{F} 3$ \\
\hline
\end{tabular}




\begin{tabular}{l|l|l}
\hline$(0.34,1,2.96)$ & $(2.3,8.74,8.74)$ & $\mathrm{F} 4$ \\
\hline$(0.34,1,2.96)$ & $(1.71,7.14,8.65)$ & $\mathrm{F} 5$ \\
\hline$(0.22,1,4.64)$ & $(1.44,3.03,8.57)$ & $\mathrm{F} 6$ \\
\hline$(0.34,1,2.96)$ & $(2.29,8.01,8.70)$ & $\mathrm{F} 7$ \\
\hline$(0.34,1,2.96)$ & $(1.71,7.14,8.65)$ & $\mathrm{F} 8$ \\
\hline$(0.35,1,2.87)$ & $(1.68,6.81,8.25)$ & $\mathrm{F} 9$ \\
\hline$(0.34,1,2.96)$ & $(2.29,8.64,8.70)$ & $\mathrm{F} 10$ \\
\hline$(0.21,1,4.84)$ & $(1.03,2.28,8.49)$ & $\mathrm{F} 11$ \\
\hline
\end{tabular}

After that, the intervals $S_{i}$ (concordance or utility measures) and $R_{i}$ (discordance or regret measures) are calculated using the following equations:

$\sum_{i=1}^{n} w_{j} \frac{f_{j}^{*}-f_{i j}}{f_{j}^{*}-f_{j}^{-}}=S_{i}$

$R_{i}=\max \left[w_{j} \frac{f_{j}^{*}-f_{i j}}{f_{j}^{*}-f_{j}^{-}}\right]$

These values are described in Table 8.

Table 8 - Utility and regret measures in Fuzzy VIKOR method

\begin{tabular}{c|c|c}
\hline $\begin{array}{c}\text { Regret measure } \\
\boldsymbol{R}_{\boldsymbol{i}}\end{array}$ & Utility measure $\boldsymbol{S}_{\boldsymbol{i}}$ & Alternative \\
\hline$(0.03,0.16,0.25)$ & $(0.33,0.50,0.59)$ & $\mathrm{A} 1$ \\
\hline$(0.10,0.15,0.25)$ & $(0.35,0.68,0.87)$ & $\mathrm{A} 2$ \\
\hline$(0.03,0.11,0.16)$ & $(0.38,0.49,0.56)$ & $\mathrm{A} 3$ \\
\hline$(0.10,0.16,0.24)$ & $(0.37,0.65,0.85)$ & $\mathrm{A} 4$ \\
\hline$(0,0.04,0.05)$ & $(0.15,0.16,0.20)$ & $\mathrm{A} 5$ \\
\hline$(0.03,0.04,0.05)$ & $(0.04,0.15,0.22)$ & $\mathrm{A} 6$ \\
\hline$(0.01,0.04,0.05)$ & $(0.14,0.15,0.19)$ & $\mathrm{A} 7$ \\
\hline$(0.02,0.07,0.09)$ & $(0.15,0.16,0.17)$ & $\mathrm{A} 8$ \\
\hline$(0.06,0.07,0.11)$ & $(0.23,0.38,0.39)$ & $\mathrm{A} 9$ \\
\hline$(0.03,0.11,0.16)$ & $(0.34,0.45,0.48)$ & $\mathrm{A} 10$ \\
\hline
\end{tabular}




\begin{tabular}{l|l|l}
\hline$(0.05,0.07,0.11)$ & $(0.05,0.27,0.33)$ & $\mathrm{A} 11$ \\
\hline$(0.07,0.07,0.11)$ & $(0.15,0.34,0.35)$ & $\mathrm{A} 12$ \\
\hline$(0.10,0.11,0.17)$ & $(0.34,0.60,0.77)$ & $\mathrm{A} 13$ \\
\hline$(0.06,0.07,0.11)$ & $(0.08,0.33,0.39)$ & $\mathrm{A} 14$ \\
\hline$(0.07,0.11,0.15)$ & $(0.25,0.45,0.52)$ & $\mathrm{A} 15$ \\
\hline$(0.07,0.07,0.12)$ & $(0.19,0.39,0.40)$ & $\mathrm{A} 16$ \\
\hline$(0.07,0.11,0.17)$ & $(0.25,0.43,0.49)$ & $\mathrm{A} 17$ \\
\hline$(0.03,0.11,0.15)$ & $(0.40,0.47,0.50)$ & $\mathrm{A} 18$ \\
\hline$(0.10,0.10,0.14)$ & $(0.22,0.51,0.64)$ & $\mathrm{A} 19$ \\
\hline$(0.12,0.14,0.29)$ & $(0.02,0.44,0.79)$ & $\mathrm{A} 20$ \\
\hline
\end{tabular}

In this step, to rank the alternatives considered, the distance $Q_{i}$ is obtained using the following equation:

$$
Q_{i}=v \frac{S_{i}-S^{*}}{S^{-}-S^{*}}+(1-v) \frac{R_{i}-R^{*}}{R^{-}-R^{*}}
$$

Where $S^{*}=\min S_{i}, R^{*}=\min R_{i}, R=\max R_{i}$, and $v=0.5$. The values for this index can be seen in Table 9.

Table 9 - VIKOR index values in Fuzzy VIKOR method

\begin{tabular}{c|c|c|c}
\hline $\begin{array}{c}\text { Fuzzy VIKOR } \\
\text { index value }\end{array}$ & Alternative & $\begin{array}{c}\text { Fuzzy VIKOR index } \\
\text { value }\end{array}$ & Alternative \\
\hline$(0.30,0.45,0.64)$ & $\mathrm{A} 11$ & $(0.81,0.83,1.33)$ & $\mathrm{A} 1$ \\
\hline$(0.33,0.49,1.06)$ & $\mathrm{A} 12$ & $(0.92,1,1.85)$ & $\mathrm{A} 2$ \\
\hline$(0.74,0.75,1.81)$ & $\mathrm{A} 13$ & $(0.62,0.65,1.44)$ & $\mathrm{A} 3$ \\
\hline$(0.31,0.50,0.82)$ & $\mathrm{A} 14$ & $(0.91,0.97,1.89)$ & $\mathrm{A} 4$ \\
\hline$(0.57,0.63,1.34)$ & $\mathrm{A} 15$ & $(0.09,0.30,0.58)$ & $\mathrm{A} 5$ \\
\hline$(0.38,0.52,1.14)$ & $\mathrm{A} 16$ & $(0.06,0.30,0.45)$ & $\mathrm{A} 6$ \\
\hline$(0.59,0.64,1.34)$ & $\mathrm{A} 17$ & $(0.08,0.29,0.63)$ & $\mathrm{A} 7$ \\
\hline$(0.60,0.62,1.49)$ & $\mathrm{A} 18$ & $(0.13,0.38,0.69)$ & $\mathrm{A} 8$ \\
\hline
\end{tabular}




\begin{tabular}{l|l|l|l}
\hline$(0.61,0.65,1.47)$ & A19 & $(0.36,0.50,1.16)$ & A9 \\
\hline$(0.72,0.97,1)$ & A20 & $(0.58,0.62,1.34)$ & A10 \\
\hline
\end{tabular}

After calculating the VIKOR index, in order to rank the alternatives, the values of this index must be defuzzified according to the equation 20 , which is the basis for the ranking of the alternatives. These values can be seen in Table 10.

Table 10 - Ranking of alternatives of the building roof and structure selection by

Fuzzy VIKOR method

\begin{tabular}{l|l|l}
\hline \multicolumn{1}{|c|}{ Ranking } & $\begin{array}{c}\text { VIKOR index } \\
\text { value }\end{array}$ & Alternative \\
\hline 17 & 0.912404 & A1 \\
\hline 20 & 1.128801 & A2 \\
\hline 11 & 0.760608 & A3 \\
\hline 19 & 1.115896 & A4 \\
\hline 3 & 0.209248 & A5 \\
\hline 1 & 0.16687 & A6 \\
\hline 2 & 0.208849 & A7 \\
\hline 4 & 0.267736 & A8 \\
\hline 8 & 0.516488 & A9 \\
\hline 12 & 0.714971 & A10 \\
\hline 5 & 0.382459 & A11 \\
\hline 7 & 0.475975 & A12 \\
\hline 18 & 0.926421 & A13 \\
\hline 6 & 0.426941 & A14 \\
\hline 10 & 0.709236 & A15 \\
\hline 9 & 0.53016 & A16 \\
\hline 13 & 0.717327 & A17 \\
\hline 14 & 0.750164 & A19 \\
\hline 15 & 0.759288 & \\
\hline
\end{tabular}




\begin{tabular}{l|l|l}
\hline 16 & 0.806096 & A20 \\
\hline
\end{tabular}

Taking into account the weight of the factors from the previous stage, the rankings of alternatives of the building roof and structure selection were calculated using the Fuzzy VIKOR method. These rankings are as follows:

1. Block and joist roof with concrete structure, 2. Block and joist roof with bolted structure, 3. Block and joist roof with steel structure, 4. Composite roof with bolted structure, 5. Chromite roof with concrete structure, 6 . Chromite roof with bolted structure, 7. Chromite roof with steel structure, 8 . Composite roof with steel structure, 9. Steel deck roof with steel structure, 10. Steel deck roof with bolted structure, 11. Concrete slab roof (one way and two way) with concrete structure, 12. Prestressed block and joist roof with concrete structure, 13. Cobiax roof with concrete structure, 14 . Roofix roof with concrete structure, 15 . Roofix roof with steel structure, 16. Roofix roof with bolted structure, 17. Barrel vault roof with steel structure, 18. Chromite roof with brick structure, 19. Block and joist roof with brick structure, 20. Barrel vault roof with brick structure.

As it can be seen, the first three priorities are of the joist and the block roof, which can be constructed with concrete, bolted and steel structure. This priority is discussable for that: 1. the block and joist roof construction does not require specialist work force or equipment and is also constructible by ordinary workers. 2. The piling during the roof construction makes these types of roof less vibrant than other ones. 3 . The shuttering under the roofs is performed only by piling and installing four cutters at specified distances, and there is no need for specialist persons who do shuttering and reinforcement of reinforced concrete roofs. 4 . The block and joist roof can be quickly and easily installed, and it does not require time consuming and costly workshop jobs. 5. Blocks and joists are produced in industrial plants under the supervision of quality control, and less manpower is required to do this. 6 . The use of hollow blocks reduces concrete consumption, which is cost-effective. 7. These roofs have high strength against horizontal forces such as wind and earthquake. 8 . Blocks and joists are lightweight and their transportation does not require the use of a crane, since they can be transported by workers to the floors. 9. Tensile concrete in block and joist 
roofs are replaced by blocks. This is the reason why these types of roofs are cost-effective. 10. Due to the block and joist roof construction, it is possible to simultaneously construct several roofs and there is no need to use roof jacks. 11. Block and joist roofs are an acoustic, thermal and humidity isolation, and their strength is very high against fires.

As can be seen, the first priority is related to buildings with block and joist roofs and concrete structures. Concrete structure is preferred to steel and bolted ones. This priority is discussable because: 1. the main material of the concrete, which is sand, can almost be abundantly found. This makes it possible to construct concrete structures. 2. Concrete structures are more resistant to atmospheric factors than steel ones, as a result, they have a longer service life. 3. Concrete structures are more resistant to fire than steel structures. 4. In concrete structures, the credit can be gradually injected into the project, while in steel structures, it is necessary to spend a great deal on the purchase of iron at the beginning. 5 . In concrete structures, in contrast to steel ones, gradual activity can be made, so that during roof and structure construction of higher levels, it is possible to simultaneously conduct internal works in the lower floors, which will increase the speed of the project.

In contrast, the least priority is of the brick structure. This priority can also be discussed because today, the brick structure is less used, with the advent of concrete, steel and bolted structures. Since the letter have a high strength against natural hazards, including earthquakes. In this type of structure, the bearing of the building live and dead loads is the responsibility of brick walls, which have very low strength, and therefore, in many cases, they are reinforced with rebar. The brick structure is inexpensive and cost-effective because of the abundance and availability of its materials, but it does not have the necessary strength against the load entered by the earthquake. Therefore, the construction of these types of structure must be prevented, especially in countries such as Iran, which is one of the world's earthquake-prone areas. Bricks structures are also rejected because of the limitations in the number of floors compared to buildings with steel and concrete structures.

\section{Conclusion}


Today, housing is among the most basic and sensitive sectors in economic and social development planning. In Iran, efforts are also being made to integrate and enhance the collection of knowledge, including the construction industry. Due to the importance of the roof and structure in construction, in this study, a decision support system is designed for construction contractors to select the building roof and structure. Initially, factors affecting the building roof and structure selection and its alternatives were extracted, according to opinions of experts and specialist, by studying relevant researches. Since each study, especially field studies, encounters obstacles and problems, which in practice creates limitations for the researcher, the use of pair-wise comparisons in AHP method, and according to experts' opinions is recommended to rank the alternatives. Due to the use of AHP method in this study, other multi-criteria decision-making methods such as SAW, TOPSIS, and so on can be used to rank and prioritize indicators.

\section{References}

Tahouni, Shapour. (2000). Office to develop and promote national building regulations, the Manual of Welding and Welding Connections in Steel Buildings, First ed., Tehran, Management Publications.

Abdullahnejad, Ibrahim, Nazari, Ahad, and Sabahi, Mahdi. (2016). A Multi-criteria DecisionMaking System to Evaluate Sustainable Buildings Using AHP, TOPSIS with Fuzzy Approach, International Conference on Civil Engineering, Architecture and Urban Development Elite, Tehran, Karin Saramad Hamayesh Institute, https://www.civilica.com/Paper-CAUPE01CAUPE01_067.html

3. Jozi, A., Seif-ol-sadat, H. (2014). Environmental Risk Assessment of Gotvan-Olia Dam at Operational phase Using the Integrated Method of Environmental Failure Mode and Effects Analysis (EFMEA) and Preliminary Hazard Analysis, Journal of Environmental Studies, Volume 40, Number 1. Pages 107-120.

Bilali, Vahid. (2010). Application of Multi-Criteria Decision-Making Methods in the Selection of Appropriate Building System, Master's Thesis, Civil Engineering, Department of Civil Engineering.

Goodarzi, Mohammad Reza, Hasanvand, Ayub. (2015). Investigating the Combined Use of Multi-criteria Decision-making Methods in Construction Management, the International Conference on Architecture, Civil Engineering and Urban Development in the Third Millennium, Tehran, July 2015. 
Bilali, Vahid, Hosseini, Abdullah, Zahraei, Banafsheh, Roozbahani, Abbas. (2011). Selection of Right Building System Using Group AHP Multi-Criteria Decision Making, the Sixth Congress of Civil Engineering, 6th and 7th May 2011, Semnan University.

Abbasian, Eztaal et al. (2014). Identification of Factors Affecting the Competitive Advantage of Active Companies in Construction Industry, Scientific Journal of Housing Economy, pp. 91-116.

Rezaian, Alireza, Hosseini, Seyed Amir Hossein. (2015). Selection of Optimal Building System Using Multi-criteria Decision-making Methods with an Emphasis on Three Methods TOPSIS, SAW and AHP, Structural and Construction Engineering, Volime 2, No. 2, pp. 16-27.

Ghannadi asl, Amin, Asvadi, Farimah. (2017). Selection of Optimal Bulding System Using Multi-Criteria Decision Making Methods with an Emphasis on AHP Method, Fourth National Conference on Modern Building Technologies: Sustainable Development and Building Technologies.

Pan, N.-F. (2008). Fuzzy AHP approach for selecting the suitable bridge construction method. Automation in construction, 17(8): p. 958-965.

Häuplik-Meusburger, S., B. Sommer, and M. Aguzzi. (2009). Inflatable technologies: adaptability from dream to reality. Acta Astronautica, 65(5-6): p. 841-852

Florez, L., D. Castro, and J. Irizarry. (2013). Measuring sustainability perceptions of construction materials. Construction Innovation, 13(2): p. 217-234.

Akadiri, P.O., P.O. Olomolaiye, and E.A. Chinyio. (2013). Multi-criteria evaluation model for the selection of sustainable materials for building projects. Automation in Construction, 30: p. $113-125$

Waris, M., et al. (2014). Criteria for the selection of sustainable onsite construction equipment. International Journal of Sustainable Built Environment, 3(1): p. 96-110.

Chang, Y.-H. and C.-H. Yeh. (2002). A survey analysis of service quality for domestic airlines. European journal of operational research, 139(1): p. 166-177.

Kazemi, Mahdi, Nikanfas, Ali Akbar, Ahmadamouei, Mahdiyeh. (2008). Designing a Decision Support System for the Accommodation Section of Tourism Industry, Tourism Studies, No. 8, pp. 91-116.

Mehregan, Mohammad Reza. (2004). Advanced Operational Research, Academic Book Publication, First Edition.

Ghodsipour, Seyed Hassan. (2010). Disscussions on Multiple-Criteria Decision-making, Amir Kabir University Press, Third Edition. 
